\title{
Atuação do Tribunal de Justiça de São Paulo com relação ao direito de crianças e adolescentes à educação*
}

\author{
ADRIANA DRAGONE SILVEIRA \\ Universidade Federal do Paraná
}

\section{INTRODUÇÃO}

$\mathrm{Na}$ Constituição Federal de 1988 (CF/1988), os direitos sociais, ${ }^{1}$ enunciados em capítulo próprio, formam, segundo Bonavides (2009, p. 374), a "espinha dorsal do Estado social brasileiro". No entanto, o autor indaga se esses direitos têm "caráter absoluto ou relativo". Seriam eles da mesma natureza e grau dos demais direitos fundamentais, como os chamados direitos de liberdade, ou comporiam uma categoria distinta, com implicações para o seu reconhecimento ou execução pelo Estado?

* Texto apresentado no Grupo de Trabalho Estado e Política Educacional (GT-05), da 34a Reunião Anual da ANPEd, realizada em Natal - RN, de 2 a 5 de outubro de 2011, baseado em discussão apresentada na tese de doutoramento da autora intitulada $O \mathrm{di}$ reito à educação de crianças e adolescentes: análise da atuação do Tribunal de Justiça de São Paulo (1991-2008), premiada como Tese Destaque USP na área de ciências humanas, sob orientação do professor doutor Romualdo Portela de Oliveira

1 Direitos sociais declarados na CF/1988: "a educação, a saúde, a alimentação, o trabalho, a moradia, o lazer, a segurança, a previdência social, a proteção à maternidade e à infância, a assistência aos desamparados" (Brasil, 1988, art. 6º. 
Autores como Holmes e Sunstein (1999), Abramovich e Courtis (2002), argumentam que todos os direitos são positivos e demandam algum tipo de prestação pública para a sua efetivação, pois, mesmo a proteção dos direitos de liberdade e os direitos políticos dependem da ação de agentes governamentais e de estrutura pública; por exemplo, a manutenção da justiça e da segurança pública, sendo esses mantidos pelo erário público. Assim, a diferença entre os direitos seria de grau.

Abramovich propõe quatro "níveis" de obrigações estatais que caracterizam cada direito: obrigações de respeitar, proteger, garantir e promover o direito:

As obrigações de respeitar se definem pelo dever do Estado de não interferir nem obstaculizar ou impedir o acesso ao desfrute dos bens que constituem o objeto do direito. As obrigações de proteger consistem em evitar que terceiros interfiram, obstaculizem ou impeçam o acesso a esses bens. As obrigações de garantir pressupõem assegurar que o titular do direito tenha acesso ao bem quando não puder fazê-lo por si mesmo. As obrigações de promover se caracterizam pelo dever de criar condições para que os titulares do direito tenham acesso ao bem. (2005, p. 194-195, grifos nossos)

Tais níveis de obrigações são aplicáveis tanto aos direitos civis e políticos como aos direitos econômicos, sociais e culturais. Todavia, a faceta mais visível desses direitos refere-se às obrigações de fazer, por isso, às vezes, são denominados direitos de prestação (Abramovich; Courtis, 2002).

Para a garantia do direito à educação, são necessários os quatro níveis de obrigações estatais. As obrigações de promover são, efetivamente, as mais onerosas, pois se referem à prestação de um serviço, construindo e mantendo diferentes unidades de ensino.

Dessa forma, fica patente que os direitos sociais necessitam de financiamento para a sua realização, e estes são "caros". "O direito da criança, para que tenha a devida instrução, necessita de proteção com eficácia e com financiamento. Deve-se ter este realismo, pois, caso contrário, o Direito embora proclamado, fica inócuo" (Cury, 1998, p. 10).

Portanto, como destaca Bobbio (2004), os direitos sociais obtêm com relativa facilidade a sua declaração, contudo, no momento de executá-los iniciam-se as reservas e oposições. Não se trata de um problema filosófico, mas político, não se busca justificá-los, mas sim protegê-los, pois "à medida que as pretensões aumentam, a satisfação delas torna-se cada vez mais difícil” (p. 80).

Todavia, é preciso destacar que a qualificação de um direito social como direito pleno não é simplesmente a conduta cumprida pelo Estado, mas a existência de algum poder jurídico para que o titular do direito possa, em caso de descumprimento da obrigação devida, exigir a sua autuação (Abramovich; Courtis, 2002). Essa garantia é prevista na $\mathrm{CF} / 1988$, art. 5º, inc. XXXV: "A lei não excluirá da apreciação do Poder Judiciário lesão ou ameaça a direito". 
Diante dessas indagações e considerações, este artigo analisa a atuação do Tribunal de Justiça de São Paulo (TJ-SP) em relação aos litígios envolvendo a educação, sejam eles por ação ou omissão do Poder Público, verificando em quais assuntos se estabeleceu uma jurisprudência favorável para a exigibilidade do direito à educação por meio do Poder Judiciário e as principais dificuldades quanto à interpretação desse direito.

Optou-se pela análise de decisões educacionais de um TJ estadual, pois os processos versando sobre os interesses da União, do estado, do município e da Fazenda Pública devem, quando a sentença for contrária a esses interesses, seguir em recurso, havendo ou não apelação da parte vencida. Sendo assim, ao exigir o cumprimento do direito à educação, a sentença judicial somente terá efeito depois de confirmada pelo TJ, ou seja, após recurso à instância superior. $\mathrm{O}$ princípio do duplo grau de jurisdição visa evitar a possibilidade de haver abuso de poder e erro por parte do magistrado, possibilitando à parte vencida reclamar a decisão a outro órgão judiciário hierarquicamente superior para reexame. Esse fato aliou-se à constatação referente à escassez de pesquisas focadas nesse órgão de justiça e à educação.

Considerando que a declaração do Estatuto da Criança e Adolescente (ECA) foi um importante ordenador jurídico para a defesa dos direitos da infância e juventude, especialmente com inovações no campo de atuação do Ministério Público (MP) para a garantia do direito da criança e do adolescente, e incluindo nesse conjunto o direito à educação, definiu-se como período de análise das decisões a partir de sua implantação. Contribuiu para essa escolha o fato de o ECA ser utilizado como um dos principais fundamentos legais nas ações judiciais versando sobre o direito à educação (Oliveira, 2007; Silveira, 2009).

Sobre a importância de se verificar a interpretação da lei pelos tribunais, Acquaviva (1995, p. 860) destaca que, embora a lei permaneça inalterada, a jurisprudência, com decisões judiciais reiteradas em determinado sentido, evolui, por isso não basta ao profissional conhecer somente a lei, mas "também o seu espírito" revelado pelos tribunais: "As leis envelhecem rapidamente, à medida que deixam de existir suas circunstâncias motivadoras, mas quase sempre são rejuvenescidas pela interpretação jurisprudencial”.

\section{EXIGIBILIDADE JUDICIAL DO DIREITO À EDUCAÇÃO}

No ordenamento jurídico brasileiro, os direitos educacionais receberam proteção jurídica diferenciada, com especificação do seu conteúdo e formas de exigibilidade, ao considerar o ensino obrigatório como direito público subjetivo. Essa norma jurídica possibilita ao indivíduo "transformar a norma geral e abstrata contida num ordenamento jurídico em algo que possua como próprio” (Duarte, 2004).

Utilizar o Judiciário para a implementação dos direitos educacionais vai além do conceito abarcado pelo direito público subjetivo relativo ao ensino 
obrigatório, pois é viável acionar o Estado para que cumpra com os deveres elencados no art. 208 da CF/1988, respeite os princípios correlacionados no art. 206, destine o percentual mínimo vinculado à educação, bem como outras regras e princípios relacionados à educação, declarados na Constituição e na legislação infraconstitucional, como a Lei de Diretrizes e Bases da Educação Nacional de 1996 (LDB/1996), o ECA, o Plano Nacional de Educação (PNE). Concernente à capacidade jurídica de exigir judicialmente esses direitos, define-se o papel relevante do reconhecimento pelo ECA, art. 208, dos direitos versando sobre interesses individuais, difusos e coletivos relativos à criança e ao adolescente, que podem ser objeto de proteção judicial.

A CF/1988 foi responsável pela ampliação de direitos civis, políticos, econômicos, sociais, culturais e os de terceira geração: direitos do consumidor, meio ambiente, qualidade de vida, além de ampliar as "estratégias e instituições das quais se pode lançar mão para invocar os tribunais”, como a ação civil pública para a representação dos direitos difusos e coletivos e a consolidação do MP para a proteção desses direitos. Em virtude desse fato, a redemocratização e o novo marco constitucional tendem "a aumentar as expectativas dos cidadãos de verem cumpridos os direitos e as garantias consignadas na Constituição, de tal forma que a execução deficiente ou inexistente de muitas políticas sociais pode transformar-se num motivo de recurso aos tribunais" (Santos, 2007, p. 18).

Todavia, algumas questões se colocam ao utilizar o Judiciário como um recurso para questionar e/ou reclamar a efetivação de direitos: Quem são os titulares desse direito? É possível exigi-lo individual ou coletivamente? A exigibilidade judicial destina-se para a determinação de vagas ou para a criação de políticas públicas? Quais mecanismos podem ser acionados em caso de sua oferta irregular ou insuficiente? (Duarte, 2006).

No entanto, quando se trata da efetivação do direito à educação e da possibilidade de exigibilidade perante o Poder Judiciário, Duarte (2006, p. 128) aponta alguns obstáculos:

1) dificuldade em delinear o regime jurídico aplicável aos direitos humanos de natureza social à luz do sistema internacional de proteção dos direitos humanos e do ordenamento jurídico interno; 2) Trata-se de verdadeiros direitos, ou de meros princípios, objetivos ou padrões de conduta gerais que devem guiar a atuação dos poderes públicos sem, contudo, gerar direitos subjetivos, exigíveis perante o Poder Judiciário, em caso de violação?; 3) o Judiciário, diante de uma situação de inércia do Legislativo na elaboração e do administrador na concretização das referidas políticas, não poderia exercer o controle sobre tais violações, sob pena de invadir a esfera de competência dos demais poderes; 4) forma de proteção diferenciada conferida às diversas etapas e modalidades educacionais, à luz do ordenamento jurídico. 
Considerando que os direitos sociais dependem da atuação ativa do Estado para a sua realização, e a sua concretização demanda impactos orçamentários, como o Poder Judiciário pode provocar a execução dessas políticas, para garantir que os direitos declarados sejam cumpridos pelos demais poderes?

E, no caso da educação, a normatização detalhada no próprio texto constitucional e nas leis infraconstitucionais, com a enumeração de princípios, deveres do Estado para a sua efetivação, definição de responsabilidades dos entes federados e vinculação de recursos financeiros, favorece a exigibilidade judicial? Ou seja, há maior aceitação dessas demandas pelo Judiciário? Em quais litígios é possível consolidar uma jurisprudência favorável, com "a delimitação de seu conteúdo e determinação das responsabilidades das autoridades competentes" (Duarte, 2006, p. 139)?

O reconhecimento do direito à educação pelo Poder Judiciário ultrapassa a dimensão de proteção de interesses individuais, vai além da determinação para a garantia de vagas nas escolas, mas seria válido para a definição e implementação de políticas públicas, com a criação de ações concretas por parte do Poder Público, aqui entendido como Poder Executivo e Legislativo?

Para Duarte (2003, p. 45), o Judiciário, quando demandado à exigibilidade de políticas públicas, dificilmente reconhece que o Executivo e o Legislativo estejam agindo com omissão. Nesse sentido, acaba prevalecendo a "falsa ideia de que a intervenção do Judiciário em questões políticas representaria uma extrapolação de seu papel, uma intervenção indevida em assuntos orçamentários, alçada daqueles que foram eleitos para isso".

Em um Estado democrático de direito, como define a própria Constituição brasileira, o Poder Judiciário precisa repensar essas ideias. Nos últimos anos, a própria jurisprudência dos tribunais brasileiros, bem como a literatura específica, tem se posicionado favoravelmente à intervenção desta instituição, não implicando ofensa ao princípio da separação dos poderes ou interferência na discricionariedade administrativa.

A complexidade dos problemas sociais contemporâneos coloca novos desafios aos direitos sociais, com o surgimento de demandas inéditas por direitos e, consequentemente, por uma efetividade das políticas públicas, implicando custos elevados para a sua implantação. Porém, tais demandas surgem num contexto de contenção da capacidade econômico-financeira do Estado e de retração das políticas sociais. O processo se torna mais complexo na realidade brasileira, pois a CF/1988 desencadeia a tentativa de construção de Estado de bem-estar, justamente no momento histórico marcado por uma crise mundial relativa a esse modelo de Estado. Isto é, no contexto de difusão da agenda neoliberal, que defende o controle dos gastos públicos e a retração das estruturas do Estado. 


\section{DECISÕES EDUCACIONAIS DO TRIBUNAL DE JUSTIÇA DE SÃO PAULO}

As decisões judiciais do TJ-SP versando sobre o direito de crianças e adolescentes à educação foram coletadas em diferentes fontes, principalmente na publicação Infância e juventude: interpretação jurisprudencial do MP (São Paulo, 2002), revista Jurisprudência do Tribunal de Justiça de São Paulo, e nos seguintes sítios eletrônicos: Sistema de Biblioteca Eletrônica do TJ-SP; ${ }^{2}$ banco de dados Consulta de jurisprudência do TJ-SP. ${ }^{3}$

A partir dessas informações, é importante destacar que as decisões coletadas no âmbito desta pesquisa constituem-se de um conjunto ilustrativo, não podendo ser considerado uma amostra do que foi julgado pelo TJ-SP referente ao direito de crianças e adolescentes à educação. Assim, totalizaram 483 decisões, no período de 1991 a 2008, que foram utilizadas para a análise da atuação do TJ paulista sobre o direito à educação. Ainda se faz relevante destacar:

[...] que uma boa parte dos casos não atinge os tribunais. É que eles se tornam objeto de acordos, transações e compromissos durante o inquérito civil, aquela parte do processo em que se preparam as provas e se faz uma instrução inquisitorial da ação. De outro lado é muito difícil constatar, à moda das ciências naturais, a "validade social" das normas apenas pela contagem de casos. A partir dos casos judiciais pode-se ter uma ideia do que é a interpretação mais corrente de certa esfera da cultura. (Lopes, 2006, p. 223)

Importante também considerar que as ações judiciais são procedimentos em recurso, pois tentativas anteriores foram utilizadas para a garantia e/ou questionamento do direito (Santos et al.,1996). As decisões coletadas foram classificadas com base nas principais demandas e questionamentos discutidos nos processos, em sete amplas categorias: acesso à educação básica; permanência; responsabilidade estatal; poder de regulação estatal; decisões administrativas e políticas; gestão dos recursos públicos; deveres dos pais (Quadro 1).

2 Disponível em: $<$ http://www.biblioteca.tj.sp.gov.br/acervo/principal.nsf $>$. Acesso em: 28 abr. 2009.

3 Disponível em:<http://cjo.tj.sp.gov.br/esaj/jurisprudencia/consultaCompleta>. Acesso em: 2 maio 2009. 


\section{Quadro 1 - Organização das decisões por categorias e temas}

\begin{tabular}{|c|c|}
\hline Categorias & Temas \\
\hline \multirow{6}{*}{$\begin{array}{l}\text { Acesso à educação básica } \\
284 \text { decisões }\end{array}$} & Acesso à educação infantil \\
\hline & Acesso ao ensino fundamental \\
\hline & Acesso ao ensino médio \\
\hline & Acesso à Educação de Jovens e Adultos (EJA) \\
\hline & Acesso à educação profissional \\
\hline & Acesso à educação especial \\
\hline \multirow{3}{*}{$\begin{array}{l}\text { Permanência } \\
36 \text { decisões }\end{array}$} & Violação às normas escolares \\
\hline & Cancelamento de matrícula em curso de língua estrangeira \\
\hline & Evasão escolar \\
\hline \multirow{3}{*}{$\begin{array}{l}\text { Responsabilidade estatal } \\
35 \text { decisões }\end{array}$} & Transporte \\
\hline & Ações de reparação de danos \\
\hline & Condições de funcionamento das escolas \\
\hline \multirow{2}{*}{$\begin{array}{l}\text { Poder de regulação estatal } \\
67 \text { decisões }\end{array}$} & Mensalidade escolar \\
\hline & Autorização/credenciamento \\
\hline \multirow{4}{*}{$\begin{array}{l}\text { Decisões administrativas e políticas } \\
36 \text { decisões }\end{array}$} & Competência para legislar \\
\hline & Reorganização das escolas estaduais \\
\hline & Municipalização \\
\hline & Fechamento de creche no período de férias \\
\hline \multirow{4}{*}{$\begin{array}{l}\text { Gestão dos recursos públicos } \\
14 \text { decisões }\end{array}$} & Aplicação mínima de recursos \\
\hline & $\begin{array}{c}\text { Fundo de Manutenção e Desenvolvimento do Ensino } \\
\text { Fundamental e de Valorização do Magistério (FUNDEF) }\end{array}$ \\
\hline & Contratos \\
\hline & Repasse de recursos públicos às instituições privadas \\
\hline $\begin{array}{l}\text { Deveres dos pais } \\
11 \text { decisões }\end{array}$ & Responsabilidade dos pais e responsáveis \\
\hline
\end{tabular}

Fonte: Decisões do Tribunal de Justiça de São Paulo (a partir de documentos contidos em São Paulo, 2002 e Jurisprudência do Tribunal de Justiça de São Paulo).

Elaboração da autora.

O levantamento das decisões judiciais tratando sobre o direito de crianças e adolescentes à educação denota o uso do Poder Judiciário para a resolução de conflitos nessa área, mas não em todos os assuntos. $O$ recurso judicial para requisição de uma vaga na educação básica e para o oferecimento de serviços que impedem a permanência do aluno na escola foram os conflitos mais presentes no conjunto estudado. 
Quadro 2 - Distribuição anual das decisões organizadas em categorias

\begin{tabular}{|l|c|c|c|c|c|c|c|c|c|c|}
\hline CATEGORIAS/ ANO & 1991 & 1992 & 1993 & 1994 & 1995 & 1996 & 1997 & 1998 & 1999 & 2000 \\
\hline $\begin{array}{l}\text { Acesso à educação } \\
\text { básica }\end{array}$ & - & - & - & - & - & 3 & 8 & 40 & 15 & 14 \\
\hline Permanência & - & 2 & - & - & - & 1 & 1 & 1 & 3 & 6 \\
\hline Responsabilidade estatal & - & - & - & - & 1 & - & 2 & 2 & 4 & 5 \\
\hline $\begin{array}{l}\text { Poder de regulação } \\
\text { estatal }\end{array}$ & 4 & 10 & 4 & 2 & 1 & 12 & 6 & 2 & 2 & 3 \\
\hline $\begin{array}{l}\text { Decisões administrativas } \\
\text { e políticas }\end{array}$ & 1 & - & 1 & 2 & - & - & 1 & 1 & 1 & 2 \\
\hline $\begin{array}{l}\text { Gestão dos recursos } \\
\text { públicos }\end{array}$ & - & - & - & 1 & - & - & 1 & 1 & - & - \\
\hline Deveres dos pais & - & - & - & - & - & 1 & - & - & - & - \\
\hline Total & $\mathbf{5}$ & $\mathbf{1 2}$ & $\mathbf{5}$ & $\mathbf{5}$ & $\mathbf{2}$ & $\mathbf{1 7}$ & $\mathbf{1 9}$ & $\mathbf{4 7}$ & $\mathbf{2 5}$ & $\mathbf{3 0}$ \\
\hline
\end{tabular}

\begin{tabular}{|l|c|c|c|c|c|c|c|c|c|}
\hline CATEGORIAS/ ANO & 2001 & $\mathbf{2 0 0 2}$ & $\mathbf{2 0 0 3}$ & $\mathbf{2 0 0 4}$ & $\mathbf{2 0 0 5}$ & $\mathbf{2 0 0 6}$ & $\mathbf{2 0 0 7}$ & $\mathbf{2 0 0 8}$ & Total \\
\hline $\begin{array}{l}\text { Acesso à educação } \\
\text { básica }\end{array}$ & 15 & 34 & 13 & 3 & 10 & 46 & 48 & 35 & $\mathbf{2 8 4}$ \\
\hline Permanência & 1 & 2 & - & - & - & 5 & 9 & 5 & 36 \\
\hline Responsabilidade estatal & 2 & 1 & - & 2 & 2 & 5 & 5 & 4 & $\mathbf{3 5}$ \\
\hline $\begin{array}{l}\text { Poder de regulação } \\
\text { estatal }\end{array}$ & 3 & - & - & 1 & 1 & 2 & 12 & 2 & $\mathbf{6 7}$ \\
\hline $\begin{array}{l}\text { Decisões administrativas } \\
\text { e políticas }\end{array}$ & - & 2 & 7 & 6 & 1 & 2 & 4 & 5 & 36 \\
\hline $\begin{array}{l}\text { Gestão dos recursos } \\
\text { públicos }\end{array}$ & - & - & 2 & - & - & 1 & 1 & 7 & $\mathbf{1 4}$ \\
\hline Deveres dos pais & 3 & 1 & - & 3 & - & 1 & 2 & - & 11 \\
\hline Total & $\mathbf{2 4}$ & $\mathbf{4 0}$ & $\mathbf{2 2}$ & $\mathbf{1 5}$ & $\mathbf{1 4}$ & $\mathbf{6 2}$ & $\mathbf{8 1}$ & $\mathbf{5 8}$ & $\mathbf{4 8 3}$ \\
\hline
\end{tabular}

Fonte: Decisões do Tribunal de Justiça de São Paulo (a partir de documentos contidos em São Paulo, 2002 e Jurisprudência do Tribunal de Justiça de São Paulo).

Elaboração da autora.

As decisões focadas nas responsabilidades do Estado quanto ao oferecimento de transporte escolar são julgadas a partir de 1999 e representam 2,8\% do total analisado. Já os processos requerendo reparação de danos, tanto morais como materiais, representam 3,7\%, sendo localizadas entre os anos de 1995 e 2008. As ações sobre as condições de funcionamento da escola, discutindo a construção de instalações educacionais adequadas e o número máximo de alunos por sala de aula também são pouco significativas no conjunto $(0,6 \%)$.

As ações que discutiram o poder do Estado na regulação das instituições privadas que exercem atividade educacional compõem o segundo maior grupo de análise deste trabalho, com $14 \%$ do total analisado. Nesse grupo, destacam-se as decisões concentradas nas mensalidades escolares das instituições privadas (9,7\%), que permearam o debate do TJ-SP sobre a educação na década de 1990, assinalando menor incidência nos últimos anos do período analisado. Os processos que questionaram o poder de regulação do Estado para autorização e credenciamento das instituições privadas representam 4,3\%. 
Entre as decisões discorrendo sobre deliberações administrativas e políticas, são enfatizadas as ações propostas pelo Poder Executivo que colocam em questão a competência do Poder Legislativo para legislar sobre determinados assuntos (4,7\%). Houve menor incidência de ações, apenas $1 \%$, contestando a municipalização, reorganização das escolas estaduais e fechamento das creches no período de férias.

Os questionamentos sobre a gestão dos recursos públicos correspondem a um pequeno percentual das decisões coletadas $(2,8 \%)$, sendo mais presente os que discutem a forma de aplicação dos recursos vinculados à educação.

Do conjunto de decisões investigadas neste trabalho, 2,3\% estão focadas nos deveres dos pais e responsáveis quanto à sua obrigação de matricular e garantir a frequência de seus filhos na escola.

Nesse cenário de crescente exigibilidade do direito à educação, merece destaque o papel exercido pelo MP, que atuou como parte em número considerável de decisões proferidas pelo TJ-SP. Também é preciso considerar a conscientização da população e da sociedade civil organizada sobre seus direitos e da possibilidade de recorrerem ao Judiciário, fazendo com que seus direitos sejam levados a sério, na expressão de Santos (2007).

Entre as demandas educacionais mais discutidas no TJ-SP, no início da década de 1990, sobressaem aquelas referentes às relações contratuais entre alunos e escola, sobretudo focadas no reajuste da mensalidade escolar. Não se estabeleceu o consenso entre os desembargadores sobre a ação do Estado para a regulação das taxas escolares.

Com a aprovação da LDB/1996 (Brasil, 1996), foi possível perceber um crescimento das demandas. Do conjunto analisado, observa-se um acentuado número de decisões nos anos de 1998, 2006, 2007 e 2008, pois a maioria das ações é levada a litígio em períodos específicos, ocasionadas por alterações nas políticas de oferta do atendimento educacional e na legislação, como as ações requisitando o direito à matrícula das crianças com 6 anos no ensino fundamental, orientações para autorização e credenciamento das instituições privadas na oferta de Educação de Jovens e Adultos (EJA), critérios para as matrículas nos cursos de língua estrangeira da rede estadual paulista e, principalmente, no que se refere às ações envolvendo a educação infantil, sua expressiva demanda pode estar relacionada à sua declaração na LDB/1996, como primeira etapa da educação básica e também ao contexto de restrição de recursos com a vinculação de recursos ao ensino fundamental, com a aprovação da emenda constitucional n. 14/96 e com a criação do Fundo de Manutenção e Desenvolvimento do Ensino Fundamental e de Valorização do Magistério (FUNDEF).

A procura pelo Judiciário é em sua maioria a busca pela efetivação de um direito. Em outros casos, o ingresso com a ação judicial corresponde a uma tentativa de evitar reformas nas políticas educacionais, como a municipalização do ensino fundamental e reorganização das escolas estaduais, sendo a tutela jurisdicional, para as entidades de classe como o Sindicato dos Professores do Ensino Oficial do Estado de São Paulo (APEOESP), uma das tentativas de reversão da política e de 
defesa dos interesses da categoria. Porém, como destacado por Carvalho (2004), as demandas sociais que não agregam interesse suficiente, ou que envolvem altos custos para que sejam efetivadas, têm mais dificuldade de ser acatadas pelo Judiciário, que opta por posição de não interferência.

Taylor (2007) destaca que os tribunais inferiores, por suas decisões serem passíveis de recursos, acabam funcionando como mecanismo de protelação, atrasando a implementação de uma política ou limitando as alternativas. Para exemplificar, podem ser citadas as liminares que concederam o direito aos alunos com 6 anos incompletos a se matricularem no ensino fundamental, a alteração na legislação para a permanência dos alunos que concluíram o ensino médio nos cursos de língua estrangeira oferecidos pela rede estadual, a paralisação do processo de reorganização das escolas estaduais em dado município.

Das decisões analisadas, denota-se que em muitas ações há discordância entre os próprios membros do tribunal, e distintos resultados da primeira e segunda instâncias do Poder Judiciário.

Nas ações que requisitavam vagas em instituições de educação infantil, os municípios, como réus ou recorrentes das ações judiciais, alegaram que são obrigados a oferecer somente o ensino fundamental, que não possuem estrutura, pois operam no limite da capacidade, e que a ampliação do atendimento na educação infantil é inviabilizada pelo problema orçamentário, não sendo possível ao Poder Judiciário interferir em atos do Poder Executivo. As decisões judiciais, tanto em primeira instância como em recurso no TJ-SP, apresentaram resultados diferentes, não havendo consenso entre os desembargadores acerca da interferência do Judiciário sobre a determinação do município em atender, por exemplo, aos pedidos de vaga, pois essa tarefa consiste numa atividade discricionária do Poder Executivo. As ações que exigiam a implementação e/ou continuidade de programa de transporte escolar também foram decididas de maneira muito distinta pelos membros do TJ-SP que apreciaram essas demandas.

As análises do Judiciário, sobretudo quanto às demandas envolvendo matrícula na educação infantil, consolidaram o dever do Estado, com responsabilidade do município pelo atendimento, ao decidirem que a primeira etapa da educação básica se constituiu em direito subjetivo dos seus titulares em exigir o seu cumprimento perante o Judiciário, quando da sua violação. Assim como definiu que não deve ser considerada uma norma programática, como justificaram vários municípios quando compelidos judicialmente para garantir esse direito às crianças que não obtiveram vagas nas creches e pré-escolas. Outrossim, foi claramente entendido pelo TJ-SP que o atendimento especializado às crianças e adolescentes com necessidades educacionais especiais não configura meramente uma norma programática.

As ações versando sobre o acesso ao ensino fundamental foram prontamente atendidas em primeira instância e confirmadas pelo TJ-SP em virtude da existência de vagas. Já a educação infantil teve seu reconhecimento como direito líquido e certo para as ações que requisitavam vagas individualmente ou para um número definido de crianças. 
Em alguns conflitos, a utilização de atos normativos dos conselhos de educação poderia favorecer o julgamento pelos membros do Judiciário, esclarecendo as questões educacionais já debatidas por esses órgãos normativos. Todavia, este trabalho evidenciou que não há referências a pareceres, resoluções e/ou indicações dos conselhos.

Mesmo não tendo informações para todo o conjunto de decisões analisadas, pode-se perceber a demora em uma resposta definitiva do Judiciário. As ações que obtiveram liminares de tutela antecipada favoráveis em primeira instância asseguraram que o direito requisitado fosse garantido, como, por exemplo, a matrícula, o transporte. Esperar a decisão do mérito do pedido poderá não surtir mais o efeito pretendido, pois, como no exemplo, a criança já poderá ter perdido a oportunidade de frequentar a escola naquele ano.

\section{APONTAMENTOS DA PESQUISA}

O processo de expansão do Judiciário para efetivar os direitos sociais garantidos na legislação está relacionado ao contexto de especificação dos direitos, mas também de crise do Estado-providência, de precarização dos direitos econômicos e sociais, com a desresponsabilização do Estado de seu papel provedor (Arantes, 2007; Santos, 2007).

O crescimento da procura pelo Judiciário também está relacionado à ampliação dos mecanismos de acesso à justiça para os atores coletivos (Arantes, 2007), ao fortalecimento de instituições e instrumentos processuais para a proteção dos direitos transindividuais.

Com relação aos instrumentos jurídicos para a exigibilidade do direito à educação, destacam-se o impacto do ECA, ao ampliar a atuação do MP para a garantia dos direitos individuais indisponíveis, difusos e coletivos referentes à criança e ao adolescente, e os diferentes instrumentos processuais existentes (ação civil pública, mandado de segurança, ação coletiva).

Efetivamente, nesse contexto, observa-se o uso dos tribunais para requerer ou questionar ações do Poder Público, relativas aos direitos educacionais no Brasil e, como foi objeto de análise neste artigo, em São Paulo. O levantamento das decisões proferidas pelo TJ-SP, no período de 1991 a 2008, possibilitou verificar o uso expressivo do Judiciário para a busca de resolução de conflitos na área educacional, principalmente na última década.

Mas, o Judiciário, quando demandado, reconheceu que a administração pública tem se omitido na concretização dos direitos educacionais? Das decisões proferidas pelo TJ-SP, envolvendo direitos educacionais, pode-se inferir que em algumas demandas consolidou-se uma jurisprudência favorável à exigibilidade por meio do Judiciário, determinando que o Executivo cumprisse com suas atribuições. Em contrapartida, persiste uma tendência, ainda que minoritária no TJ-SP, de recorrer ao argumento central da impossibilidade de o Judiciário intervir em atos que sejam da esfera exclusiva do Executivo, tendência essa prevalente em demandas concentradas na deliberação política. 
Verifica-se que na educação subsiste um conjunto bem definido de direitos, indicando que os principais problemas ligados a essa questão não se referem a qualquer suposta indefinição. Em algumas áreas, como educação infantil e educação especial, o Judiciário contribuiu para esclarecer a legislação, principalmente quanto aos deveres do Estado.

De modo específico, referente à declaração do direito à educação e seu aprimoramento para possível exigibilidade perante o Judiciário, sobressai a necessidade de definição de regras para o princípio da "qualidade do ensino", contendo determinações e competências entre os entes responsáveis para que possa ser juridicamente exequível definir quando da sua não satisfação, pois as demandas que de certa maneira reivindicavam esse aspecto do direito foram escassas, e as que solicitavam medidas com relação à construção de instalações educacionais adequadas, bem como a definição do número de alunos por sala de aula, não tiveram solução favorável no âmbito do Judiciário.

Vale ainda destacar que estabelecer a extensão do conteúdo da qualidade do ensino é uma tarefa técnica e política, e não dos membros do Judiciário, pois "definir insumos e parâmetros para um ensino de qualidade requer uma análise dos custos, das condições reais, dos objetivos que se almeja e das expectativas sociais em torno do processo de escolarização" (Oliveira; Araujo, 2005, p. 18).

Observou-se que nas demandas relacionadas às questões técnicas ou políticas os desembargadores foram mais resistentes em aceitar os pedidos, justificando com a impossibilidade de interferência do Judiciário em matéria específica do Executivo. Todavia, Abramovich e Courtis (2002) evidenciam que a possibilidade de êxito do caso será maior se for factível demarcar de maneira clara, por exemplo, o projeto, as prioridades ou a implementação das políticas públicas.

A utilização do Judiciário para reivindicar e questionar políticas relacionadas à educação, principalmente nesta década, tem permitido mudança de atitude por parte dos membros do Judiciário. Um exemplo paradigmático refere-se à exigibilidade da educação infantil; inicialmente com sentenças diferenciadas em primeira instância, e até mesmo por parte dos desembargadores do TJ-SP. Desse modo, consolidou-se uma jurisprudência favorável ao longo dos anos, sobretudo com as decisões proferidas pelo Supremo Tribunal Federal (STF). Sabe-se que as decisões favoráveis conferem maior visibilidade à possibilidade de reclamar e conseguir judicialmente o direito pretendido.

A aceitação diferenciada da exigibilidade do direito à educação pelo Judiciário não se refere à proteção distinta no ordenamento jurídico brasileiro às etapas e modalidades da educação brasileira, mas ao caráter das disputas.

Nos processos que discutiam a omissão, principalmente para a criação de oportunidades que garantam a fruição do direito, como vagas, notou-se que há mais facilidade de os desembargadores acatarem a possibilidade de exigir o cumprimento por parte da autoridade competente. Sob outro aspecto, nos litígios que questionavam medidas já tomadas pela administração pública, ou seja, por ação do Executivo, o Judiciário tende a não interferência, considerando que a atividade faz 
parte do poder discricionário do Executivo, sendo aceitas as que individualmente impediam o acesso das crianças e dos adolescentes a vagas, como nos processos sobre restrição da idade para ingresso no ensino fundamental e extinção de classes de educação de jovens e adultos.

A tese da ingerência do Judiciário em atividade discricionária do Poder Executivo foi apresentada, principalmente, nos processos que discutiam as medidas administrativas e políticas adotadas pelo Poder Público, como a reorganização das escolas no estado de São Paulo, construção de salas de aulas e programas de transporte escolar. Nesse último caso, entende-se que um direito claramente assegurado pela Constituição e pela LDB, como dever do Estado, deixou de ser cumprido. Nessas ações, o tribunal não enfrentou as demandas colocadas a este Poder, seja por não acreditar que tivesse "força" para tanto ou porque não desejasse enfrentá-las, decidindo com base em critérios formais para o não prosseguimento da ação.

Quanto à aceitação das demandas, observou-se que as concernentes a pedidos individuais ou para um número definido de interessados apresentaram tendência majoritariamente favorável entre os membros do TJ-SP, ao contrário das que abrangiam interesses coletivos, com argumentos de pedidos genéricos e indeterminados e, sobretudo, com o fundamento de impossibilidade de interferência do Judiciário no planejamento municipal e na questão orçamentária. Essa tendência de facilidade de aceitação das ações quando os demandantes são nomeados e identificados também foi captada por Oliveira (1995) e Lopes (2006).

Se as demandas judiciais com pedidos individuais são acatadas de modo mais favorável pelo Judiciário, salienta-se a relevância de identificar as crianças que necessitam de vagas nas instituições de ensino, principalmente com realização de censos.

Das decisões envolvendo o direito à educação, denota-se que o principal obstáculo à efetivação consiste em cumprir o que foi consagrado pela legislação, colocar em ação as prioridades e as metas estabelecidas para garantir o atendimento dos deveres impostos ao Estado, construindo instituições educacionais com infraestrutura adequada, principalmente em áreas de expansão na cidade e no campo, equipando os estabelecimentos de ensino com materiais necessários ao ensino e aprendizagem adequados, promovendo capacitação dos profissionais da educação, remunerando-os com dignidade para que possam se dedicar exclusivamente ao exercício do magistério. Ou seja, é preciso sair da igualdade jurídica e implantar políticas públicas que garantam, de fato, igualdade de oportunidades e de conhecimentos a todos os cidadãos brasileiros.

De acordo com Piovesan (2007, p. 74), a justiciabilidade dos direitos econômicos, sociais e culturais no Brasil é capaz de gerar um legado transformador e emancipatório para a consolidação do Judiciário em "locus de afirmação de direitos". Para tanto, a autora destaca como fundamental a participação da sociedade civil organizada, para que esta "acione de forma crescente o Poder Judiciário, otimizando o potencial emancipatório e transformador que o direito pode ter. Só assim haverá maior transparência e accountability dos deveres do Estado no tocante à implementação dos direitos à saúde e à educação" (idem, ibidem). 
Com relação à educação, para que o Judiciário se converta, utilizando-se da expressão de Piovesan (2007), em um "locus de afirmação de direitos”, torna-se fundamental, também como reiterou esta pesquisa, a mudança de concepção de parcela dos membros do Judiciário no que se refere à sua interferência no controle da ação da administração pública, quando esta deixa de cumprir a sua função, pois, se a administração não cumpre a lei, há fundamento para que os cidadãos exercitem seu direito contra o Estado. Segundo essa diretriz, o Judiciário não está invadindo atribuições do Poder Executivo ou Legislativo, mas respeitando uma exigência da Constituição.

Ao discutir neste artigo o controle exercido pelo Poder Judiciário para a garantia do direito à educação, não se desconsidera ou desvaloriza a participação como mecanismo de construção da democracia, mas ressalta-se que o sistema de justiça pode ser um espaço fundamental para o seu aprimoramento, ao possibilitar a reivindicação dos direitos proclamados para além da defesa dos direitos civis. Assim, como enfatiza Santos (2007, p. 90), "sem direitos de cidadania efetivos a democracia é uma ditadura mal disfarçada”.

As demandas judiciais constituem, nesse sentido, importante instrumento para a consolidação da democracia, ao problematizar os deveres do Estado a partir dos princípios constitucionais, e de extensão de sua concepção formal, associada à forma de governo e aos mecanismos de seleção dos representantes, para uma democracia substancial, na concretização da igualdade jurídica, social e econômica, materializando direitos fundamentais para todos, em igual conteúdo e qualidade.

\section{REFERÊNCIAS}

Abramovich, Víctor; Courtis, Christian. Linhas de trabalho em direitos econômicos, sociais e culturais: instrumentos e aliados. SUR - Revista Internacional de Direitos Humanos, São Paulo, Rede Universitária de Direitos Humanos, ano 2, n. 2, p. 188-223, 2005.

. Los derechos sociales como derechos exigibles. Madrid: Editorial Trotta, 2002.

Acquaviva, Marcus Cláudio. Dicionário jurídico brasileiro Acquaviva. São Paulo: Editora Jurídica Brasileira, 1995.

Arantes, Rogério Bastos. Judiciário: entre a justiça e a política. In: Avelar, Lúcia; Cintra, Antônio Octávio (Orgs.). Sistema político brasileiro: uma introdução. 2. ed. Rio de Janeiro: Konrad-Adenauer-Stiftung; São Paulo: Editora UNESP, 2007.

Воввіо, Norberto. A era dos direitos. Rio de Janeiro: Elsevier, 2004. Nova edição.

Bonavides, Paulo. Curso de direito constitucional.24. ed. São Paulo: Malheiros Editores, 2009.

Brasil. Constituição da República Federativa do Brasil de 1988. Disponível em: <http:// www.senado.gov.br/sf/legislacao/const/>. Acesso em: 14 ago. 2010. 
. Constituição (1988). Emenda constitucional n. 14, de 12 de setembro de 1996. Modifica os arts. 34, 208, 211 e 212 da Constituição Federal, e dá nova redação ao art. 60 do Ato das Disposições Constitucionais Transitórias. Diário Oficial da União, República Federativa do Brasil, Brasília, DF, 13 set. 1996.

. Lei n. 8.069, de 13 de julho de 1990. Dispõe sobre o Estatuto da Criança e do Adolescente e dá outras providências. Diário Oficial da União, República Federativa do Brasil, Brasília, DF, 16 jul. 1990.

. Lei n. 9.394, de 20 de dezembro de 1996. Estabelece as Diretrizes e Bases da Educação Nacional. Diário Oficial da União, República Federativa do Brasil, Brasília, DF, 23 dez. 1996.

Carvalho, Ernani Rodrigues de. Em busca da judicialização da política no Brasil: apontamentos para uma nova abordagem. Revista de Sociologia e Política, Curitiba, Universidade Federal do Paraná, n. 23, p. 115-126, 2004.

Cury, Carlos Roberto Jamil. A educação infantil como direito. In: BrasiL. Ministério da Educação e do Desporto. Subsídios para credenciamento e funcionamento de instituiçôes de educação infantil. Volume II. Brasília: MEC, 1998.

Duarte, Clarice Seixas. Direito público subjetivo e políticas educacionais. São Paulo em Perspectiva, São Paulo, Fundação SEADE, v. 18, n. 2, p. 113-118, 2004.

. O direito público subjetivo ao ensino fundamental na Constituição Federal Brasileira de 1988. 2003. Tese (Doutorado) - Faculdade de Direito, Universidade de São Paulo, São Paulo, 2003.

. Reflexões sobre a justiciabilidade do direito à educação no Brasil. In: HadDAD, Sérgio; Graciano, Mariângela (Orgs.). A educação entre os direitos humanos. Campinas: Autores Associados; São Paulo: Ação Educativa, 2006.

Holmes, Stephen; Sustein, Cass Robert. The cost of rights: why liberty depends on taxes. New York: W. W. Norton \& Companhy, 1999.

Lopes, José Reinaldo de Lima. Direitos sociais: teoria e prática. São Paulo: Método, 2006.

Oliveira, Romualdo Portela de. Educação e cidadania: o direito à educação na Constituição de 1988 da República Federativa do Brasil. 1995. Tese (Doutorado em Educação) - Faculdade de Educação, Universidade de São Paulo, São Paulo, 1995.

. O direito à educação. In: Oliveira, Romualdo Portela de; Adrião, Theresa (Orgs.). Gestão, financiamento e direito à educação: análise da LDB e da Constituição Federal. 3. ed. São Paulo: Xamã, 2007.

; Araujo, Gilda Cardoso de. Qualidade do ensino: uma nova dimensão da luta pelo direito à educação. Revista Brasileira de Educação, Rio de Janeiro, ANPEd; Campinas: Autores Associados, n. 28, p. 5-23, jan./abr. 2005.

Piovesan, Flávia. Justiciabilidade dos direitos sociais e econômicos: desafios e perspectivas. In: Silva, Roberto B. Dias da (Coord.). Direito constitucional. Temas atuais. Homenagem à professora Leda Pereira da Mota. São Paulo: Método, 2007. 
São Paulo (Estado). Ministério Público. Infância e juventude: interpretação jurisprudencial. Centro de Apoio Operacional das Promotorias de Justiça da Infância e Juventude. São Paulo: Imprensa Oficial do Estado, Ministério Público, 2002.

Silveira, Adriana Dragone. Atuação do Ministério Público para a proteção do direito à educação básica. In: Ranieri, Nina Beatriz Stocco (Org.). Direito à educação: aspectos constitucionais. São Paulo: Editora da Universidade de São Paulo, 2009, v. 1, p.123-141. SAntos, Boaventura Sousa et al. Os tribunais nas sociedades contemporâneas: o caso português. Porto: Edições Afrontamento, 1996.

SAntos, Boaventura Sousa. Para uma revolução democrática da justiça. São Paulo: Cortez, 2007.

TAYlor, Matthew M. O judiciário e as políticas públicas no Brasil. Dados - Revista de Ciências Sociais, Rio de Janeiro, IUPERJ, v. 50, n. 2, p. 229-257, 2007.

\section{SOBRE A AUTORA}

Adriana Dragone Silveira é doutora em educação pela Universidade de São Paulo (USP). Professora da Universidade Federal do Paraná (UFPR). E-mail: adrianadragone@yahoo.com.br 


\section{ADRIANA DRAGONE SILVEIRA}

\section{Atuação do Tribunal de Justiça de São Paulo com relação ao direito de crianças e adolescentes à educação}

O artigo analisa como o Tribunal de Justiça de São Paulo (TJ-SP) apreciou e julgou as demandas envolvendo os direitos de crianças e adolescentes à educação, no período após a implantação do Estatuto da Criança e do Adolescente (ECA), verificando em quais assuntos se estabeleceu uma jurisprudência favorável para a exigibilidade judicial do direito à educação e as principais dificuldades quanto à interpretação desse direito. A partir da análise das decisões, observou-se que há uma tendência majoritária a aceitar com mais facilidade as demandas que requisitavam, individualmente ou para um número definido de interessados, o acesso à educação, consolidando uma jurisprudência favorável ao longo dos anos, principalmente com relação à educação infantil e à educação especial. Todavia, os desembargadores foram mais resistentes em acatar os pedidos relacionados às questões técnicas ou políticas, considerando a tese da impossibilidade de interferência do judiciário em atividade do Poder Executivo.

Palavras-chave: direito à educação; Poder Judiciário; Estatuto da Criança e do Adolescente; políticas públicas educacionais.

The procedure of Sao Paulo State Court regarding the rights of children and adolescents to education

This paper examines how Sao Paulo Justice Court assessed and judged the demands involving the rights of children and adolescents to education, in the period after the implementation of the Child and Adolescent Statute, checking on what subjects such court 
established jurisprudence favorable to the legal liability for the right to education as well as the main difficulties regarding the interpretation of this right. The analysis of decisions allows stating that there is a major tendency to accept more easily the demands of access to education from individuals or from a defined number of interested people. Over the years, such trend consolidated favorable jurisprudence, especially in relation to early childhood education and special education. However, magistrates showed greater resistance to abide by the requests related to technical or political issues, considering the thesis that the Judiciary Power must not interfere in the Executive Power activities.

Keywords: right to education; Judiciary; Child and Adolescent 'Statute; public education policies.

\section{Actuación del Tribunal de Justicia de São Paulo relacionada con el derecho de niños e adolescentes a la educación}

Este artículo examina cómo el Tribunal de Justicia de São Paulo ha analizado y juzgado las demandas relacionadas con los derechos de niños y adolescentes a la educación, en el periodo posterior a la aplicación del Estatuto de la Infancia y la Adolescencia, verificando sobre qué temas se estableció una jurisprudencia que favoreció el poder de exigencia legal por el derecho a la educación, y las principales dificultades en la interpretación de este derecho. A partir del análisis de las decisiones, se ha observado que existe una tendencia mayoritaria a aceptar más fácilmente las demandas presentadas, de forma individual o por un número determinado de partes interesadas, que solicitaban el acceso a la educación, consolidando una jurisprudencia favorable a lo largo de los años, especialmente relacionada con la educación prescolar y la educación especial. Sin embargo, los jueces han sido más resistentes a cumplir con las solicitudes relacionadas con cuestiones técnicas o politicas, teniendo en cuenta la tesis de la imposibilidad de interferencia del Judicial en las actividades del Poder Ejecutivo.

Palabras clave: derecho a la educación; Poder Judicial; Estatuto de la Infancia y Adolescencia; políticas públicas de educación. 